\title{
LIST OF AUTHORS
}

Susan Suleiman - 515 Philosophy Hall, Columbia Univ., New York, N.Y. 10027 USA.

Roger Wright - Dept. of Hispanic Studies, University of Liverpool, P.O. Box 147, Liverpool L69 3BX, England.

Susan Olson - Romance Languages, 510 Waterman Building, University of Vermont, Burlington, Vermont, 05401 USA.

C. D. Bettinson \& L. J. Newton - Dept. of French, University College, P.O. Box 95, Cardiff CF1 1XA, Wales.

C. J. Mertens - Graafseweg 284, Nijmegen, The Netherlands.

Miguel Garci-Gomez - Dept, of Romance Languages, Duke Univ., Durham, N.C. 27706 USA.

G. J. de Vries - Duitsekampweg 28c, Wolfheze, The Netherlands.

James W. Marchand - Center for Advanced Study, University of Illinois, 2072 Foreign Languages Building, Urbana, Illinois, 61801 USA.

B. Maurach - Dept. of Linguistics and Modern Languages, University of Ottawa, Ottawa, Ontario, Canada K1N 6N5.

Klaus Petersen - Dept. of German, University of Winnipeg, Winnipeg, Manitoba, Canada R2B 2EG.

W. F. Koopman - Engels Seminarium, Herengracht 330, Amsterdam, The Netherlands.

P. Verdonk - Engels Seminarium, Herengracht 330, Amsterdam, The Netherlands.

Mary Hynes-Berry - 5411 S. Harper Ave., Chicago, Illinois, 60615 USA. 